Article

\title{
Limitations of Harmonics Control in Power Converters
}

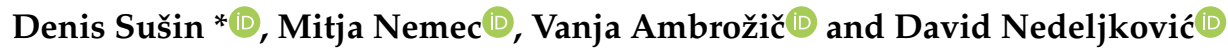 \\ Faculty of Electrical Engineering, University of Ljubljana, Tržaška 25, SI-1000 Ljubljana, Slovenia \\ * Correspondence: denis.susin@fe.uni-lj.si; Tel.: +386-1-4768-466
}

Received: 30 May 2019; Accepted: 26 June 2019; Published: 29 June 2019

\begin{abstract}
In this paper, we analyze the constraints of harmonics control in power electronic systems. Based on an equivalent circuit of a typical power converter application and its parameters, we have derived an analytical expression for calculating the maximal amplitude of controlled harmonic current. This expression has been successfully verified on an experimental setup, designed around a single-phase grid-connected bidirectional inverter. The pulse width modulated (PWM) driven inverter has been controlled by multiple resonant controllers, each of them providing individual control of a selected harmonic current. By using the derived expression and taking into account the parameters of converter application, power electronics designers could quickly determine the limitations of harmonics control.
\end{abstract}

Keywords: harmonic analysis; DC-AC power converters; current control; analytical models

\section{Introduction}

Control algorithms in power electronics devices often include harmonics control. Many power converter applications require its implementation due to harmonics emission regulations [1,2], while others use it to improve efficiency [3]. Satisfactory results can be achieved only by advanced types of controllers that are usually implemented into the current control loop, e.g., resonant, multiple resonant, or repetitive controllers. Typical applications requiring a mitigation of harmonics are grid-connected in single-phase [4] and three-phase pulse width modulated (PWM) inverters [5,6], photovoltaic systems [7], uninterruptable power supplies [8,9], active power filters [10-12], and microgrids [13]. Moreover, harmonics control is used in permanent magnet synchronous machine drives to reduce torque ripple, to compensate for dead-time effects [14,15], or to improve efficiency [3].

While studies present various modifications or new approaches $[4,13,16,17]$, all of them evaluate proposed solutions through comparison with other methods, instead of evaluating absolute performance. The current spectra or total harmonic distortion (THD) are compared in steady-state; the approach with the lowest harmonic content is deemed better. The absolute results were never discussed. Thus the methods, which should theoretically completely eliminate certain harmonics (e.g., proportional-resonant PR with multiple resonant controllers MRC in [18], Ho repetitive control in [13], etc.), fail to do so without further comments by the authors. While in some cases additional harmonics can be caused due to the dead-time effects or output filter resonance, these two cases have been studied in detail and their effects and mitigations are well known $[4,19]$. In rare occasions when the authors noted the difference between the theoretical limits of their approach and measured results, these discrepancies were disregarded as either having a low enough amplitude [20-22] or occuring above the frequency band of interest [23]. The effects of output filters on the system performance have only been studied for passive devices [24].

In order to design a system able to suppress or generate specific harmonics, a multitude of system parameters must be evaluated. This paper focuses on limitations of current harmonics control in a 
single-phase grid-connected bidirectional inverter, i.e., the capability of a system to control particular harmonics at a given converter DC link voltage. An analytical expression for calculating the maximal amplitude of individually controlled current harmonic will be derived, taking into account circuit parameters and converter operating conditions. Based on this expression, all system parameters (DC-link voltage level, output filter parameters, dead time, etc.) could be determined in such a way that physical limitations of the harmonics control are not exceeded.

\section{Methodology}

Many power electronics devices include a DC link and some kind of passive filter on the output or/and on the input. Typical representatives of these devices are grid connected converters and motor drive converters with L-filter. A simple generalized equivalent circuit of such a converter is shown in Figure 1, where the power converter is represented by an AC source with voltage $v_{S}(t)$ [25]. The task of a power converter is to generate fundamental, as well as higher harmonics. Thus, by properly generated voltage harmonics, the current harmonics can be controlled in steady-state.

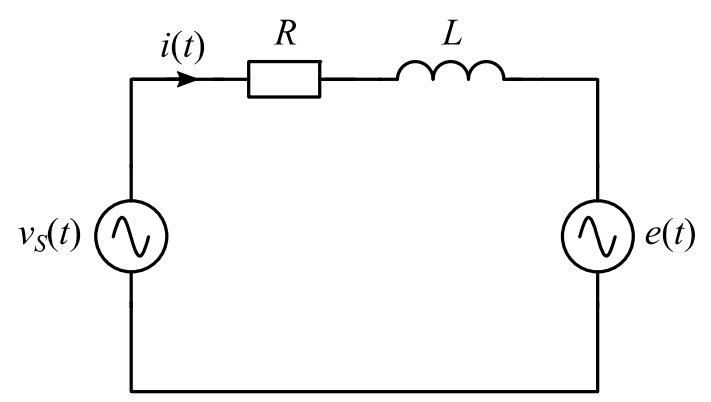

Figure 1. Equivalent circuit of a power converter application.

The load is modeled by passive elements (resistance $R$ and inductance $L$ ) and an additional AC source with voltage $e(t)$, which represents an active load, e.g., grid supply voltage or back electromotive force (BEMF) voltage of an electrical machine. The load current $i(t)$ depends on all aforementioned quantities, resulting in the following simple equation:

$$
v_{S}(t)=e(t)+R i(t)+L \frac{d i(t)}{d t}
$$

Fourier series of converter output voltage $v_{S}(t)$, load voltage $e(t)$, and load current $i(t)$ in steady-state can be written as the sums of individual harmonics:

$$
\begin{aligned}
v_{S}(t) & =\sum_{h=1}^{h_{\max }} v_{S, h}=\sum_{h=1}^{h_{\max }} \hat{V}_{h} \cos \left(h \omega_{1} t+\varphi_{V h}\right) \\
e(t) & =\sum_{h=1}^{h_{\max }} e_{h}=\sum_{h=1}^{h_{\max }} \hat{E}_{h} \cos \left(h \omega_{1} t+\varphi_{E h}\right) \\
i(t) & =\sum_{h=1}^{h_{\max }} i_{h}=\sum_{h=1}^{h_{\max }} \hat{I}_{h} \cos \left(h \omega_{1} t+\varphi_{I h}\right)
\end{aligned}
$$

with $h_{\max }$ being the highest harmonic to be controlled in a particular application.

Depending on the application, the power converter has to generate voltage harmonics in $v_{S}(t)$ to provide proper control of load current harmonics in $i(t)$. After inserting Equations (2)-(4) and time 
derivative of Equation (4) into the differential Equation (1), the following steady-state expression is obtained:

$$
\begin{aligned}
& \sum_{h=1}^{h_{\max }} \hat{V}_{h} \cos \left(h \omega_{1} t+\varphi_{V h}\right)=\sum_{h=1}^{h_{\max }} \hat{E}_{h} \cos \left(h \omega_{1} t+\varphi_{E h}\right)+ \\
& \sum_{h=1}^{h_{\max }} R \hat{I}_{h} \cos \left(h \omega_{1} t+\varphi_{I h}\right)-\sum_{h=1}^{h_{\max }} h \omega_{1} L \hat{I}_{h} \sin \left(h \omega_{1} t+\varphi_{I h}\right)
\end{aligned}
$$

The latter can be simplified to:

$$
\sum_{h=1}^{h_{\max }} \hat{V}_{h} \cos \left(h \omega_{1} t+\varphi_{V h}\right)=\sum_{h=1}^{h_{\max }}\left(\hat{E}_{h} \cos \left(h \omega_{1} t+\varphi_{E h}\right)+Z_{h} \hat{I}_{h} \cos \left(h \omega_{1} t+\varphi_{I h}+\varphi_{h}\right)\right)
$$

where $Z_{h}$ and $\varphi_{h}$ are defined as:

$$
\begin{gathered}
Z_{h}=\sqrt{R^{2}+\left(h \omega_{1} L\right)^{2}} \\
\varphi_{h}=\arctan \left(\frac{h \omega_{1} L}{R}\right)
\end{gathered}
$$

Further, for the converter voltage $v_{S}(t)$, the amplitude of its individual harmonic $\hat{V}_{h}$ and the corresponding phase angle $\varphi_{V h}$ can be calculated as:

$$
\begin{gathered}
\hat{V}_{h}=\sqrt{\hat{E}_{h}^{2}+\left(Z_{h} \hat{I}_{h}\right)^{2}+2 \hat{E}_{h} Z_{h} \hat{I}_{h} \cos \left(\varphi_{E h}-\varphi_{I h}-\varphi_{h}\right)} \\
\varphi_{V h}=\arctan \left(\frac{\hat{E}_{h} \sin \left(\varphi_{E h}\right)+Z_{h} \hat{I}_{h} \sin \left(\varphi_{I h}+\varphi_{h}\right)}{\hat{E}_{h} \cos \left(\varphi_{E h}\right)+Z_{h} \hat{I}_{h} \cos \left(\varphi_{I h}+\varphi_{h}\right)}\right)
\end{gathered}
$$

Power converter can provide maximal output voltage $V_{S \max }$, which, along with other system parameters, listed in Table 1, determines its current generating capabilities. For bipolar PWM converters in single-phase systems, $V_{S \max }$ is equal to DC link voltage $V_{D C}$, reduced by voltage loss $V_{d}$ :

$$
V_{S \max }=V_{D C}-V_{d}
$$

Table 1. System parameters imposing harmonic control limitations.

\begin{tabular}{cc}
\hline Symbol & Description \\
\hline$V_{S \max }$ & power converter maximal output voltage \\
$h$ & order of harmonic \\
$\omega_{1}$ & fundamental angular frequency of the load voltage and current \\
$R$ & load resistance \\
$L$ & load inductance \\
$\hat{E}_{h}$ & amplitude of load voltage $h$-th harmonic \\
$\hat{I}_{h}$ & amplitude of load current $h$-th harmonic \\
$\varphi_{E h}$ & phase angle of load voltage $h$-th harmonic \\
$\varphi_{I h}$ & phase angle of load current $h$-th harmonic \\
$f_{S}$ & sampling frequency \\
$t_{d}$ & dead time during transistor switching \\
$R_{T}$ & transistor's ON resistance \\
\hline
\end{tabular}

This voltage loss is caused by the converter's inevitable safety feature, dead time implementation, and depends on the applied dead time $t_{d}$, DC link voltage $V_{D C}$, and switching frequency $f_{S}$ [26]:

$$
V_{d}=2 \cdot V_{D C} \cdot t_{d} \cdot f_{S}
$$


Consequently, load current harmonics in $i(t)$ can be successfully controlled, if required converter voltage $v_{S}(t)$ remains below the saturation level:

$$
\max \left[a b s\left(v_{S}(t)\right)\right] \leq V_{S \max }
$$

Based on given $V_{S \max }$, the objective is to calculate the maximal possible load current amplitude for each harmonic. In general, it is very hard to analytically derive these relationships due to the influence of all amplitudes and phase angles. For this reason, the worst-case scenario is taken into consideration.

The worst-case scenario for each harmonic occurs when $\hat{V}_{h}$ from Equation (9) reaches its maximal value. The conditions for current harmonic control become most demanding, when for each individual harmonic, load current amplitude $\hat{I}_{h}$ is maximal, and the phase difference between the corresponding load voltage angle $\left(\varphi_{E h}\right)$ and load current angle $\left(\varphi_{I h}\right)$ equals $\varphi_{h}$.

A worst-case example is illustrated in Figure 2, where the converter has to generate fundamental voltage harmonic $v_{S, 1}$ and the additional fifth harmonic $v_{S, 5}$; the latter exhibits its amplitude $\hat{V}_{5}$ and its phase displacement $\varphi_{V 5}$, so that the converter voltage $v_{S}$ reaches its maximal value $V_{S \max }$. For the same fundamental voltage harmonic, $v_{S, 1}$ and the fifth harmonic with the same amplitude $\hat{V}_{5}$, but different phase displacement, the converter is not saturated $\left(v_{S}<V_{S \max }\right)$, as shown in Figure 3.

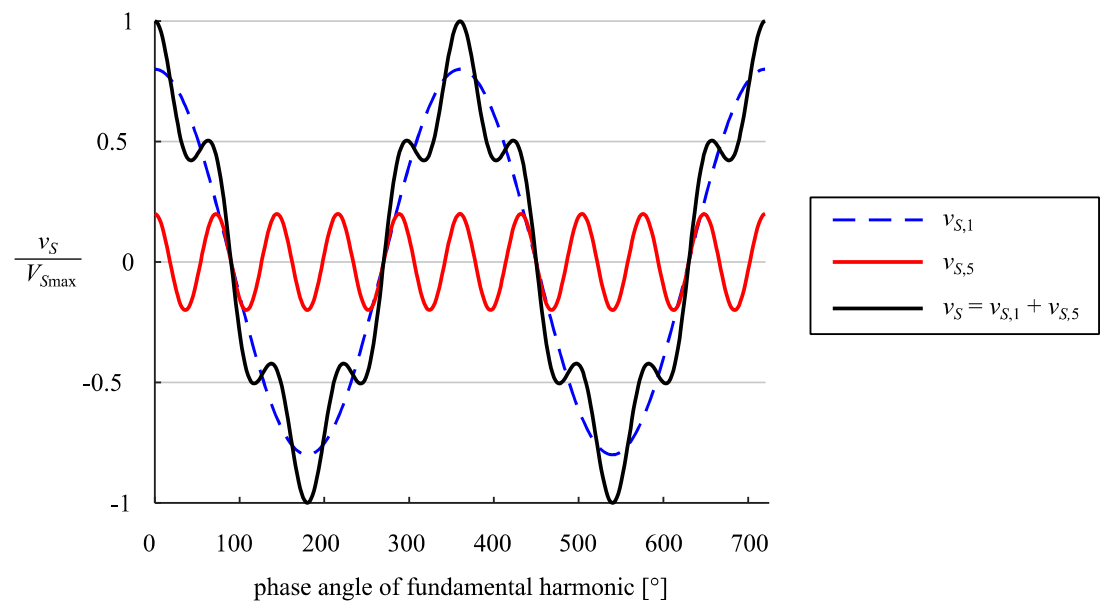

Figure 2. Converter voltage $v_{S}$ consisting of the first and fifth harmonic with phase displacement, leading to saturation (worst case scenario).

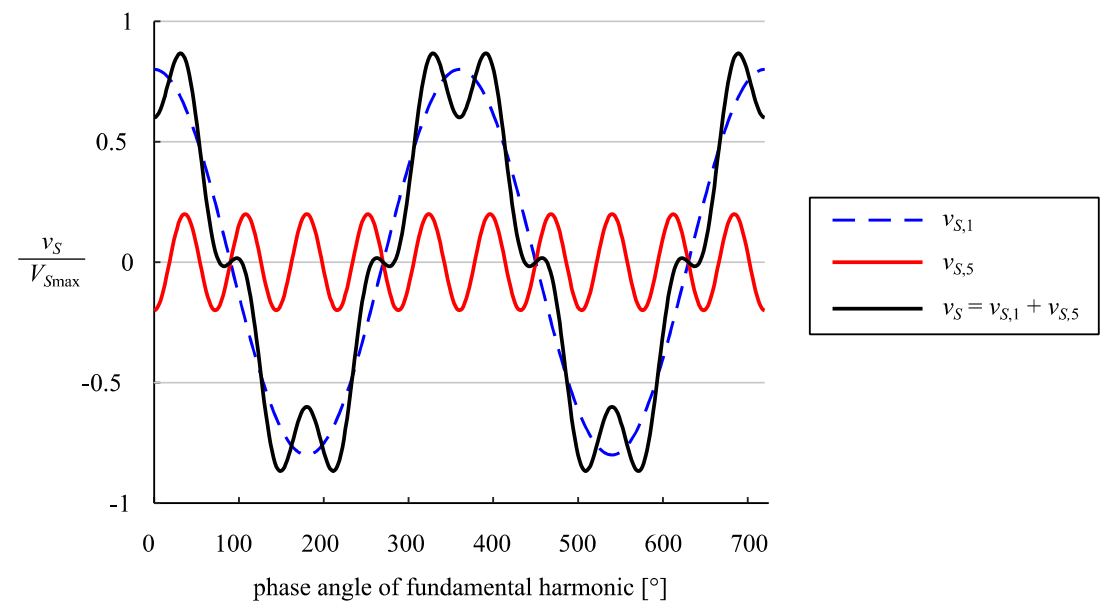

Figure 3. Converter voltage $v_{S}$ consisting of the first and fifth harmonic with the same amplitudes as in Figure 2, but different phase displacement; no saturation occurs. 
Focusing on the worst case simplifies relations in Equations (9), (10), and (13), since all the converter voltage harmonics align exactly at the angle, where their contribution to $v_{S}$ is maximal. For this case, inserting Equation (2) into Equation (13) yields an expression:

$$
\hat{V}_{1}+\sum_{h=2}^{h_{\max }}\left(\hat{E}_{h}+Z_{h} \hat{I}_{h}\right) \leq V_{S \max }
$$

where phase angles are not present any more, except for the converter voltage fundamental harmonic $\hat{V}_{1}$, which can be calculated by Equation (9) with $h=1$.

Based on Equation (14), the maximal additional load current amplitude of specific harmonic $h$ for the worst-case scenario can be calculated as:

$$
\hat{I}_{h \max }=\frac{V_{S \max }-\hat{V}_{1}-\sum_{i=2}^{h_{\max }}\left[\left(\hat{E}_{i}+Z_{i} \hat{I}_{i}\right) \cdot c_{i}\right]}{Z_{h}}
$$

where the term $c_{i}$ indicates, whether the application provides control of the $i$-th harmonic of load current $\left(c_{i}=1\right)$ or not $\left(c_{i}=0\right)$. As long as particular harmonic is not intended to be controlled, it does not need to be considered in the calculation of the maximal additional harmonic load current amplitude $\hat{I}_{h \max }$. The power converter generates just the harmonics, which are controlled via current control loop; no other harmonics contribute to the decrease of $\hat{I}_{h \max }$ in Equation (15). If only fundamental harmonic of load current is controlled, the sum in numerator of Equation (15) becomes zero.

\section{Experimental Setup}

The derived analytical expression for calculating the maximal amplitude of controlled harmonic current $\hat{I}_{h \max }$ by Equation (15) has been experimentally verified on a setup, designed around a single-phase grid-connected bidirectional inverter and L-filter are shown in Figure 4. The power transistors (metal-oxide semiconductor field effect transistors - MOSFETs) are triggered by bipolar PWM.

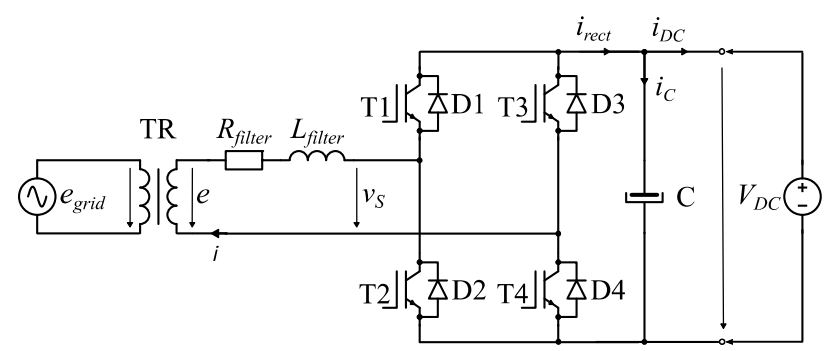

Figure 4. Schematic of single-phase grid-connected bidirectional inverter in the experimental setup.

To comply with the model from Figure 1, the equivalent load resistance $R$ and equivalent load inductance $L$ for experimental setup are calculated from power stage parameters as:

$$
\begin{gathered}
R=R_{\text {filter }}+R_{T R 2}+2 R_{T} \\
L=L_{\text {filter }}+L_{T R 2}
\end{gathered}
$$

In Equation (16) and Equation (17), $R_{T R 2}$ is AC resistance of transformer's secondary winding, $L_{T R 2}$ is leakage inductance of transformer's secondary winding, and $R_{T}$ is power transistor's ON resistance.

The load current $i$ is controlled by a proportional controller, which is supported by multiple resonant controllers, each of them providing separate control of selected harmonic current, as shown in Figure 5. This kind of control structure results in outstanding performance [18], thus any relevant 
deviations could only result from physical limitations of the system. The control algorithm has been implemented with Texas Instruments digital signal processor (DSP) TMS320F28377D. Parameters of the experimental setup (Figure 6) are given in Table 2.

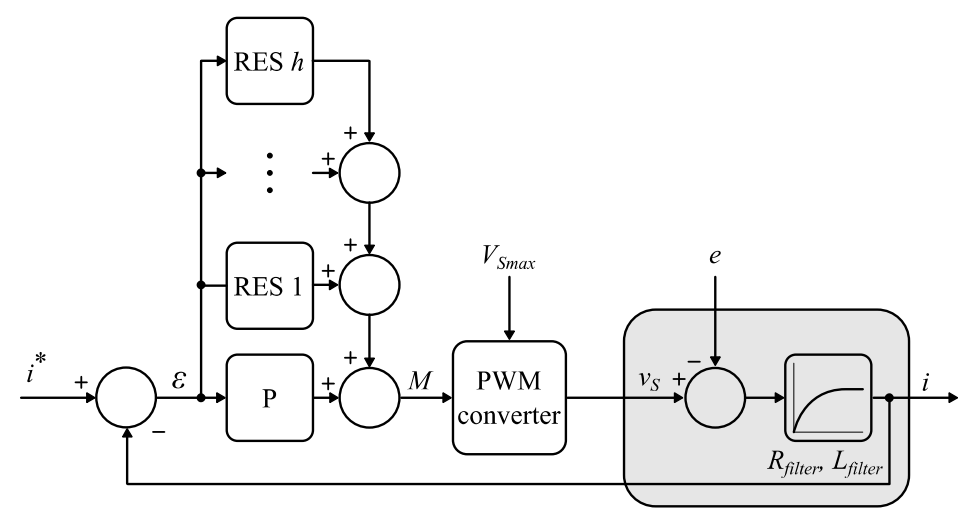

Figure 5. Block diagram of load current harmonic control with proportional $(\mathrm{P})$ and multiple resonant controllers (RES 1-RES $h$, where $h$ denotes the highest controlled harmonic).

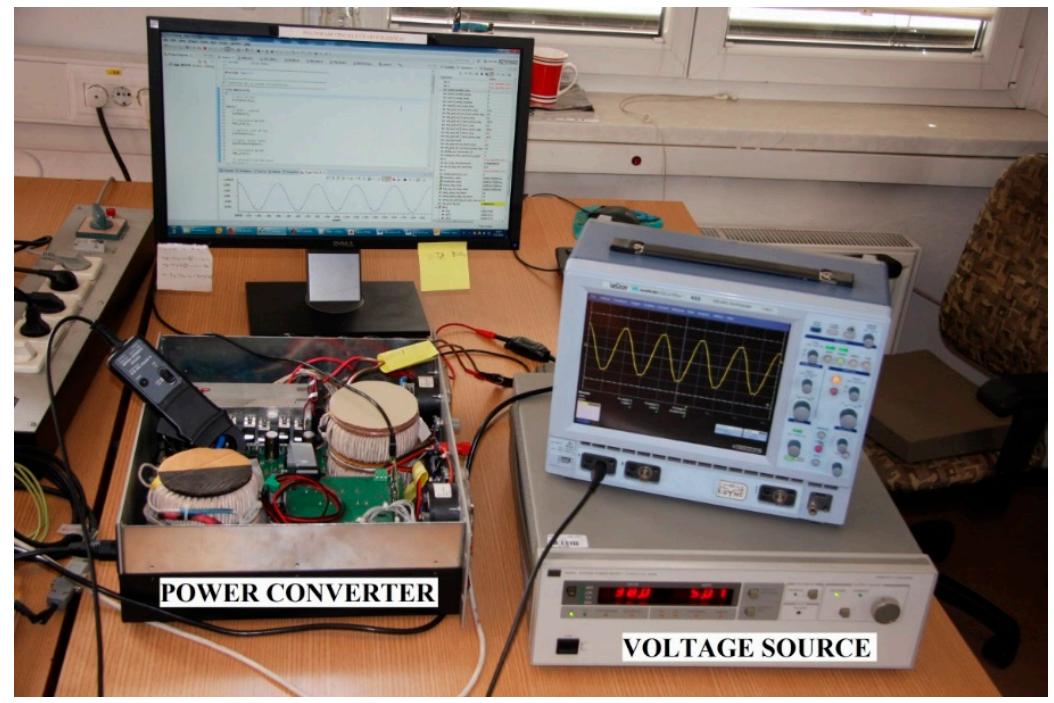

Figure 6. Experimental setup photo.

Table 2. Parameters of experimental setup.

\begin{tabular}{ccc}
\hline Symbol & Description & Test Case Values \\
\hline$R_{\text {filter }}$ & filter AC resistance & $47 \mathrm{~m} \Omega$ \\
$L_{\text {filter }}$ & filter inductance & $580 \mu \mathrm{H}$ \\
$R_{T R 2}$ & transformer AC resistance (secondary winding) & $32 \mathrm{~m} \Omega$ \\
$L_{T R 2}$ & transformer leakage inductance (secondary winding) & $8 \mu \mathrm{H}$ \\
$R_{T}$ & transistor's ON resistance & $7.2 \mathrm{~m} \Omega$ \\
$V_{D C}$ & DC link voltage & $38 \mathrm{~V}$ \\
$C$ & DC link capacitance & $41 \mathrm{mF}$ \\
$P$ & converter's nominal power & $500 \mathrm{~W}$ \\
$\hat{E}_{1}$ & amplitude of load voltage 1 1t $^{\text {st }}$ harmonic & $35.4 \mathrm{~V}$ \\
$\hat{I}_{1}$ & amplitude of load current $1^{\text {st }}$ harmonic & $10 \mathrm{~A}$ \\
$\hat{I}_{3}$ & amplitude of load current $3^{\text {rd }}$ harmonic & $1 \mathrm{~A}$ \\
$f_{1}$ & fundamental frequency of load voltage and current & $50 \mathrm{~Hz}$ \\
$f_{S}$ & sampling frequency & $20 \mathrm{kHz}$ \\
$t_{d}$ & dead time during transistor switching & $200 \mathrm{~ns}$ \\
\hline
\end{tabular}


The load current reference $i^{*}$ is determined within the DSP following Equation (4), according to the test requirements. Due to multiple resonant controllers the steady-state error is practically negligible, but only if the converter is not saturated. Namely, if modulation index $M$ from Figure 5 exceeds $100 \%$, the converter would be required to generate voltage $v_{S}(t)$ above its saturation level $V_{S \max }$. Consequently, the current harmonic distortion occurs.

Figure 7a shows how actual load current $i$ follows its reference value $i^{*}$, which consists of fundamental harmonic with amplitude of $10 \mathrm{~A}$ and $3^{\text {rd }}$ harmonic with amplitude of $1 \mathrm{~A}$. Error signal is small, as the modulation index $M$ remains slightly below $100 \%$ (Figure $7 \mathrm{~b}$ ). Corresponding frequency spectra of the load current $i$ and its reference $i^{*}$ are shown in Figure 7c.

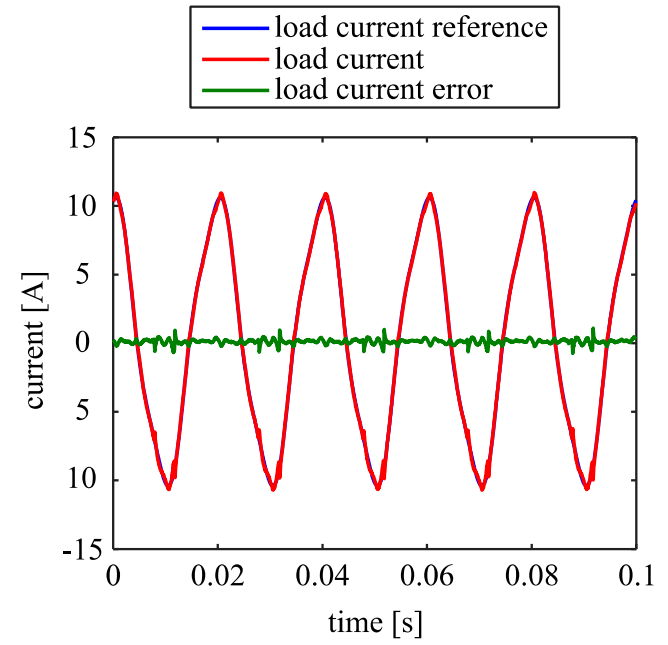

(a)

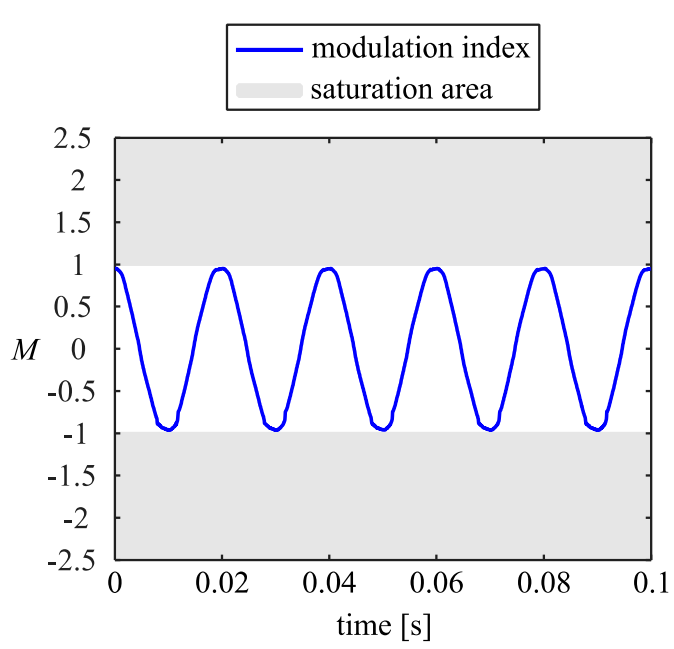

(b)

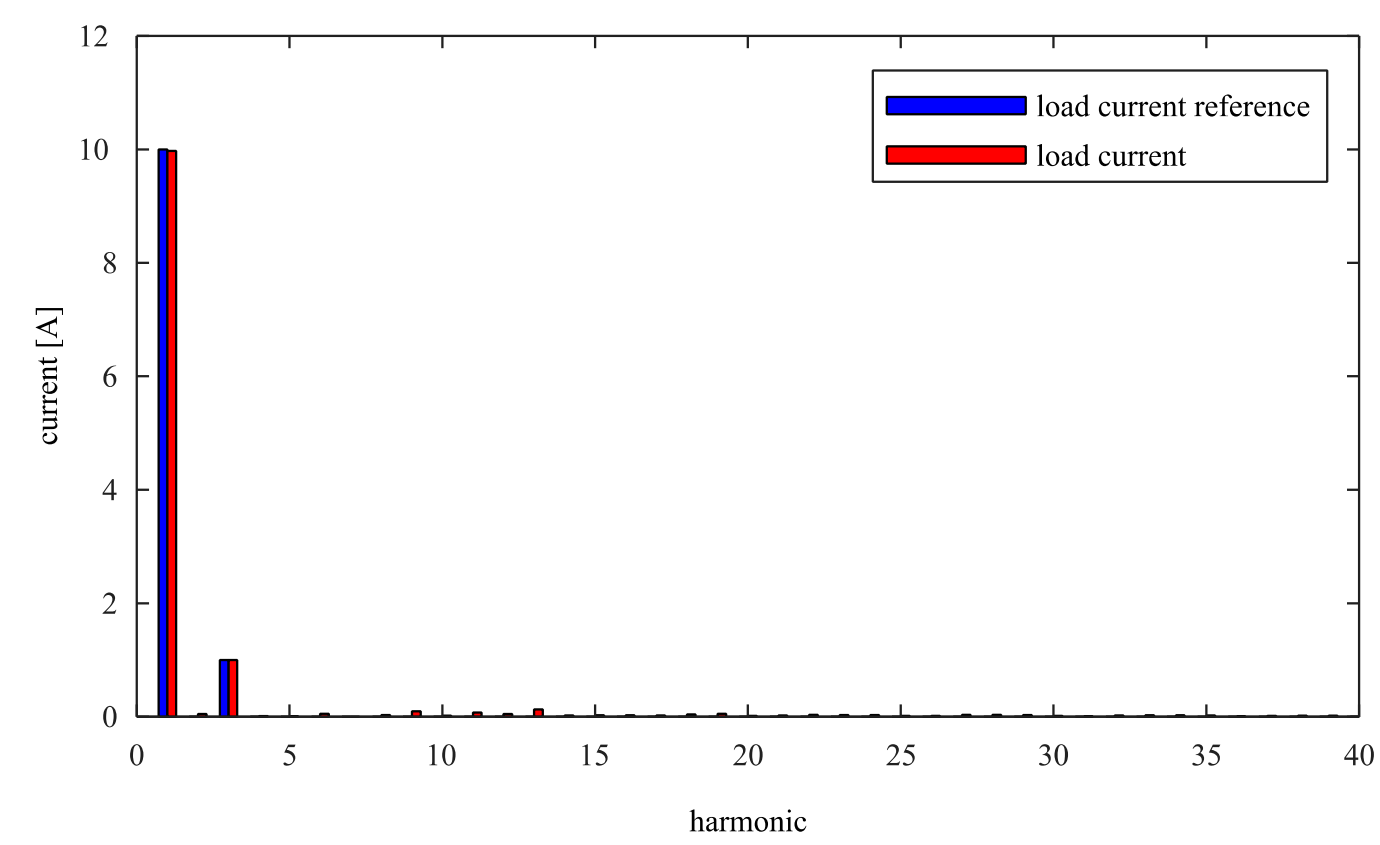

(c)

Figure 7. Power converter operating below the saturation level $V_{S \max }$; (a) Load current reference $i^{*}$ (containing fundamental harmonic with amplitude of $10 \mathrm{~A}$ and the third harmonic with amplitude of 1 A), load current $i$ and load current error $\varepsilon$; (b) modulation index $M$; (c) frequency spectra of load current reference $i^{*}$ and load current $i$. 
When the load current reference $i^{*}$ has been changed to contain fundamental harmonic with an amplitude of $10 \mathrm{~A}$ (as previously) and the third harmonic with amplitude increased to $2.3 \mathrm{~A}$, the actual load current still behaves well (Figure 8a). As seen from Figure 8b, the modulation index $M$ reaches $100 \%$, leading the power converter just to the saturation limit. Consequently, harmonic distortion of the load current still does not occur (Figure 8c). Therefore, the fundamental load current and its third harmonic are generated properly.

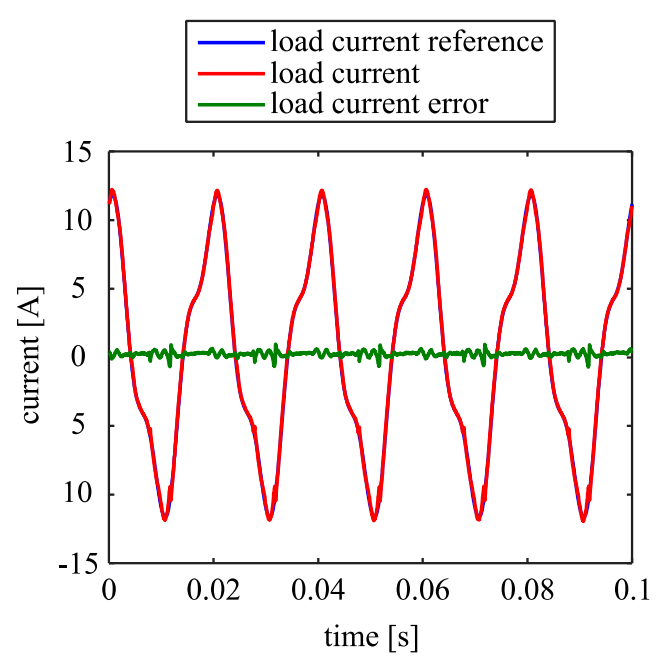

(a)

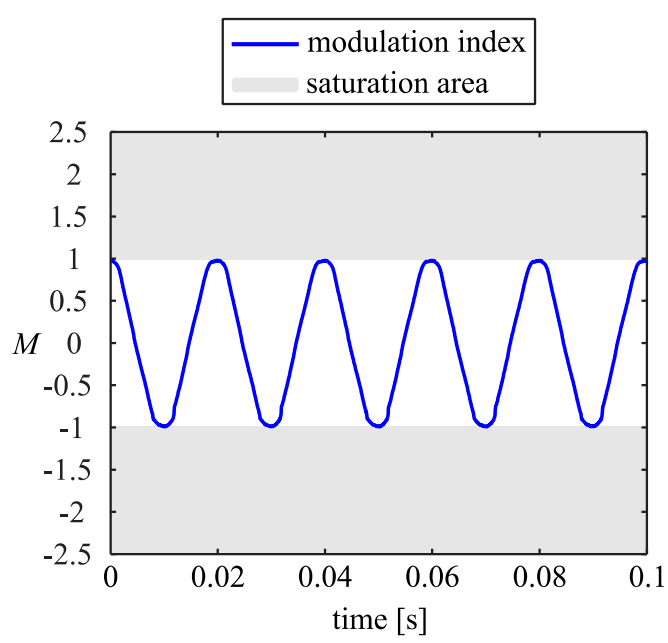

(b)

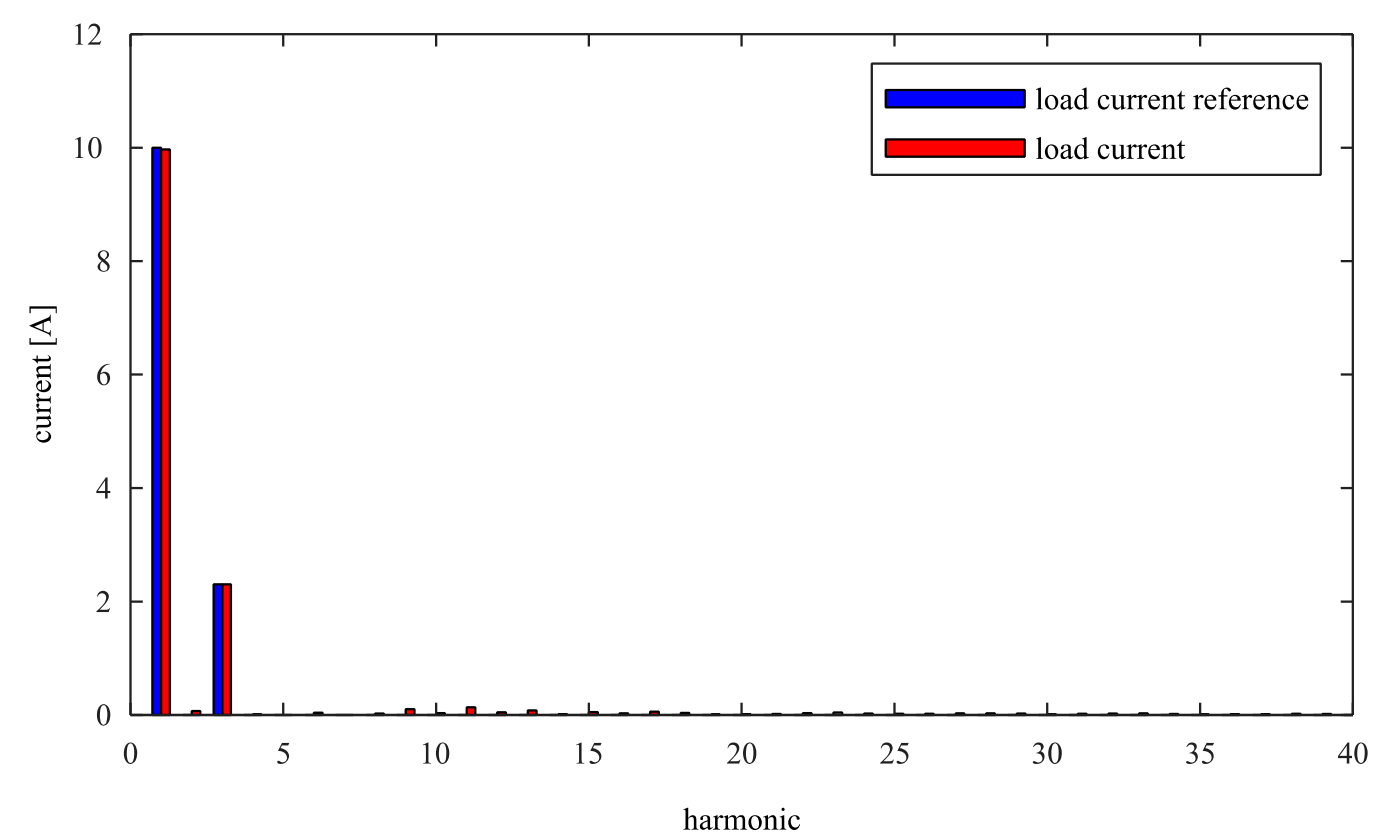

(c)

Figure 8. Power converter operating at the saturation limit $V_{S \max }$; (a) Load current reference $i^{*}$ (containing fundamental harmonic with amplitude of $10 \mathrm{~A}$ and the third harmonic with amplitude of $2.3 \mathrm{~A})$, load current $i$ and load current error $\varepsilon$; (b) modulation index $M$; (c) frequency spectra of load current reference $i^{*}$ and load current $i$.

Further increase of the load current reference third harmonic to $5 \mathrm{~A}$ (superposed to fundamental harmonic with amplitude of $10 \mathrm{~A}$ ) is shown in Figure 9a. Load current $i$ fails to follow its reference $i^{*}$, as the modulation index $M$ exceeds $100 \%$ (Figure $9 \mathrm{~b}$ ) and the converter is saturated. The difference 
between frequency spectra of load current reference $i^{*}$ and its actual value $i$ is clearly presented in Figure 9c.

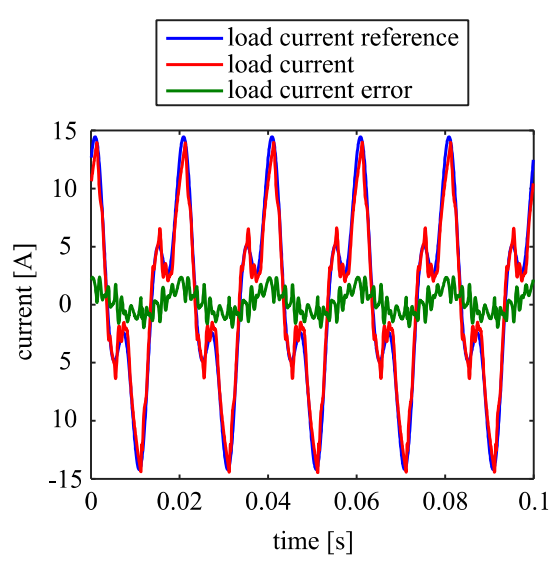

(a)

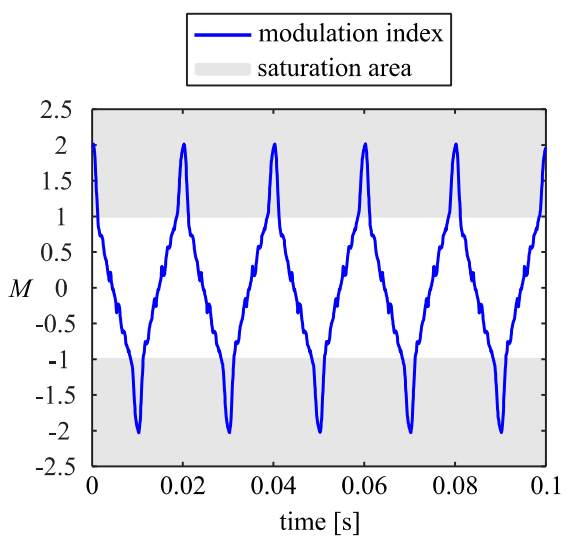

(b)

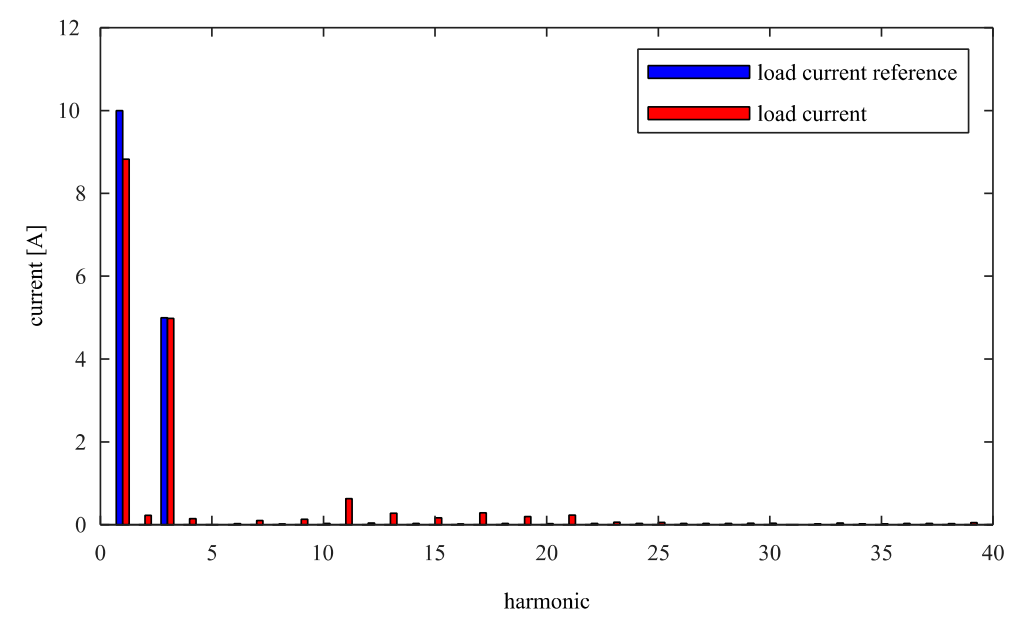

(c)

Figure 9. Power converter operating above the saturation level $V_{S \max }$ (a) Load current reference $i^{*}$ (containing fundamental harmonic with amplitude of $10 \mathrm{~A}$ and the third harmonic with amplitude of $5 \mathrm{~A})$, load current $i$ and load current error $\varepsilon$; (b) modulation index $M$; (c) frequency spectra of load current reference $i^{*}$ and load current $i$.

\section{Results}

In order to verify the theoretical findings, several measurements have been performed. The goal was to analyze what amplitude of a specific load current harmonic $\hat{I}_{h \max }$ could converter generate additionally to the already generated current (basis). Consequently, the experimental load current reference $i^{*}$ is formed by adding the selected $(h$-th) load current harmonic reference to the load current basis. To measure the converter's capability of generating maximal additional harmonic current amplitude $\hat{I}_{h \max }$, the converter is driven into saturation. The saturation is detected, if the modulation index $M$ exceeds $100 \%$; this is treated as the worst-case scenario. According to Equation (9), the saturation depends on the amplitude $\hat{I}_{h}$ and the angle of load current harmonic $\varphi_{I h}$; hence, various combinations of those two parameters have to be tested. First, low amplitude of selected load current harmonic $\hat{I}_{h}$ is set and the angle of load current harmonic $\varphi_{I h}$ is incremented in small steps, until the saturation of the converter occurs (if it occurs). If no saturation is observed for this preset amplitude of selected load current harmonic $\hat{I}_{h}$ and for any value of angle $\varphi_{I h}$, then the amplitude reference of this additionally controlled harmonic current $\hat{I}_{h}$ is slightly increased. Again, the angle of load current harmonic $\left(\varphi_{I h}\right)$ is gradually incremented from $0^{\circ}$, in expectation of eventual saturation. 
The results of two representative tests are presented. In the first test, as the basis, only the load current fundamental harmonic at $50 \mathrm{~Hz}$ with an amplitude of $10 \mathrm{~A}$ has been considered.

The procedure described above (variation of $\hat{l}_{h}$ and $\varphi_{I h}$ ) for the converter's saturation detection was repeated for each ( $h$-th) harmonic from $2^{\text {nd }}$ to $40^{\text {th }}$ (in this case-study chosen as the highest one), giving an array of corresponding experimental maximal amplitudes $\hat{I}_{h \max }$. In Figure 10, these experimental results are shown in comparison to the maximal amplitudes of the controlled harmonic current $\hat{I}_{h \max }$, calculated by the derived analytical expression Equation (15). For example, the highlighted point at the third harmonic in Figure 10 has been obtained from the measurement, shown in Figure 8a, where the load current contains a fundamental harmonic with amplitude of $10 \mathrm{~A}$ and the third harmonic with an amplitude of $2.3 \mathrm{~A}$; this load current led the converter to its saturation limit.

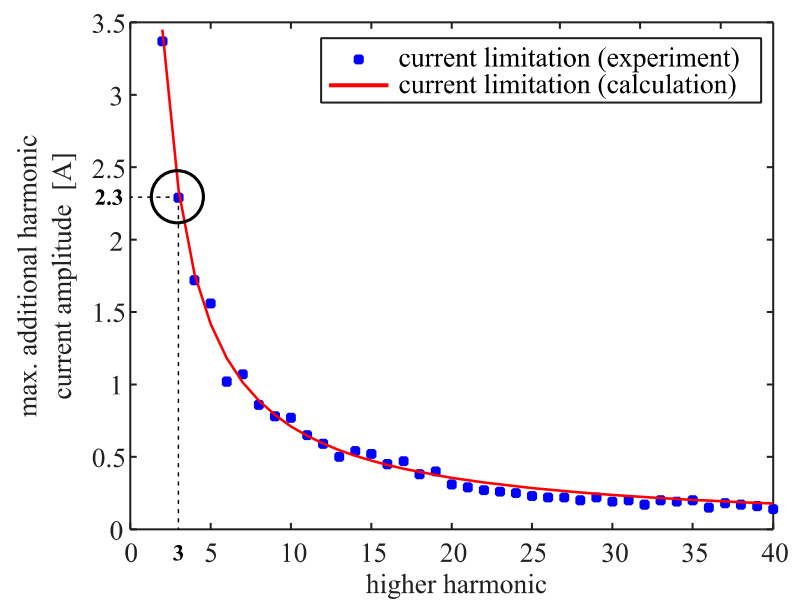

Figure 10. Comparison of calculated (by Equation (15)) and experimental current limitations, based on load current containing only fundamental harmonic with amplitude of $10 \mathrm{~A}$.

In the second test, the load current containing a fundamental harmonic with amplitude of $10 \mathrm{~A}$ and an additional third harmonic with an amplitude of $1 \mathrm{~A}$ was used as the basis. The same procedure as in the first test, i.e., adjusting the amplitude of load current harmonic $\hat{I}_{h}$ and its angle $\varphi_{I h}$ until saturation of the converter occurs, was followed to determine experimental maximal amplitudes $\hat{I}_{h \max }$ from the $2^{\text {nd }}$ to $40^{\text {th }}$ harmonic. Comparison between calculated and experimental results for the second test is shown in Figure 11.

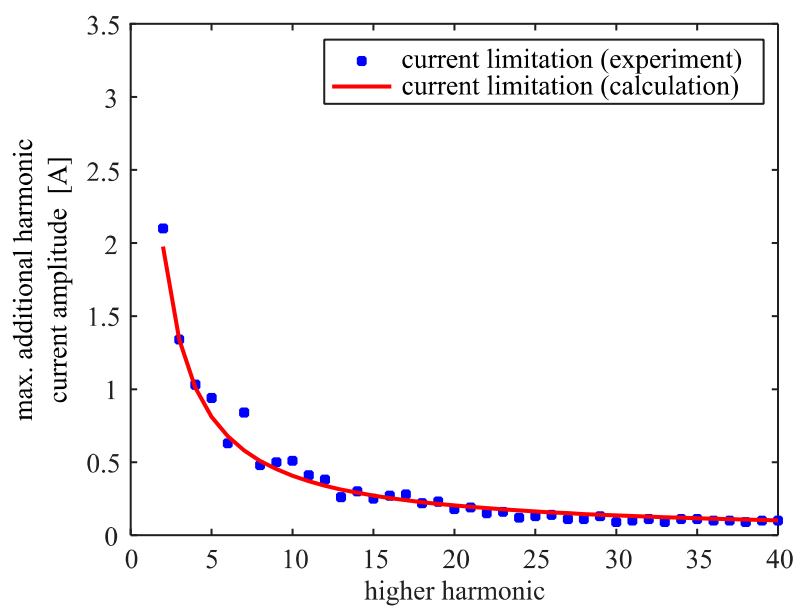

Figure 11. Comparison of the calculated (by Equation (15)) and experimental current limitations, based on load current containing fundamental harmonic with an amplitude of $10 \mathrm{~A}$ and third harmonic with amplitude of $1 \mathrm{~A}$. 
Good matching between the calculated and experimental results for both tests indicate that the derived analytical expression Equation (15) provides fast and reliable estimation of the converter harmonics limitations.

\section{Conclusions}

The derived analytical expression, used for calculating the maximal amplitude of controlled harmonic current, has been experimentally verified on the single-phase grid-connected bidirectional inverter with an L-filter. By applying the obtained expressions, power electronics designers can quickly determine required system parameters in order to avoid physical limitations of harmonic suppression/generation. Furthermore, if the harmonic suppression/generation does not act as expected (e.g. certain harmonics are not suppressed completely), this can be attributed either to physical limitations of the system or to inadequate control algorithm. In the former case, one can infer from the proposed expressions whether a simple increase of DC-link voltage is sufficient or if a complete system redesign is required.

Further research on this topic will be focused on the evaluation of the influence of temperature and parameter variation on the maximal amplitude of a controlled harmonic current. Limitations for single-phase converters with other types of passive filters (like LC, LCL, or CLC), as well as for converters in three-phase applications, will be considered.

Author Contributions: All authors have contributed equally to this work and all authors have read and approved the submitted manuscript. Conceptualization, D.S. and M.N.; Formal analysis, D.S.; Investigation, D.S. and M.N.; Methodology, D.S.; Resources, V.A. and D.N.; Software, D.S. and M.N.; Supervision, M.N., V.A. and D.N.; Validation, D.S. and D.N.; Visualization, V.A. and D.N.; Writing - original draft, D.S. and D.N.; Writing - review \& editing, M.N., V.A. and D.N.

Funding: This research received no external funding.

Acknowledgments: This research was supported in part by Slovenian Research Agency; Javna agencija za raziskovalno dejavnost Republike Slovenije, Bleiweisova cesta 30, 1000 Ljubljana, Slovenia.

Conflicts of Interest: The authors declare no conflict of interest.

\section{References}

1. IEC Standard for Harmonic Current Emissions; IEC 61000-3-2; IEC: Centurion, South Africa, 2001.

2. IEEE Standard for Interconnecting Distributed Resources with Electric Power Systems; IEEE: Piscataway, NJ, USA, 2009; pp. 1547-2003.

3. Catuogno, G.R.; Forchetti, D.G.; Leidhold, R.; Garcia, G.O. Power Flow Maximization in Permanent-Magnet Generators. IEEE Trans. Ind. Electron. 2014, 61, 6566-6573. [CrossRef]

4. Yang, Y.; Zhou, K.; Wang, H.; Blaabjerg, F. Analysis and Mitigation of Dead-Time Harmonics in the Single-Phase Full-Bridge PWM Converter with Repetitive Controllers. IEEE Trans. Ind. Appl. 2018, 54, 5343-5354. [CrossRef]

5. Schuelting, P.; van der Broeck, C.H.; Doncker, R. Analysis and Design of Repetitive Controllers for Applications in Distorted Distribution Grids. IEEE Trans. Power Electron. 2018, 34, 996-1004. [CrossRef]

6. Lidozzi, A.; Ji, C.; Solero, L.; Zanchetta, P.; Crescimbini, F. Digital dead-beat and repetitive combined control for stand-alone four-leg VSI. IEEE Trans. Ind. Appl. 2017, 53, 5624-5633. [CrossRef]

7. Lee, S.-H.; Cha, W.-J.; Kwon, B.-H.; Kim, M. Discrete-Time Repetitive Control of Flyback CCM Inverter for PV Power Applications. IEEE Trans. Ind. Electron. 2016, 63, 976-984. [CrossRef]

8. Julian, A.L.; Oriti, G.; Ji, C.; Zanchetta, P. Single Phase Energy Management System Operating in Islanding Mode with Repetitive Control and Active Damping. IEEE Trans. Ind. Appl. 2018, 54, 5163-5172. [CrossRef]

9. Lorenzini, C.; Flores, J.V.; Pereira, L.F.A.; Pereira, L.A. Resonant-Repetitive controller with phase correction applied to uninterruptible power supplies. Control Eng. Pract. 2018, 77, 118-126. [CrossRef]

10. Herman, L.; Blazic, B.; Papic, I. A control strategy of a hybrid active filter for operation with harmonically unbalanced voltages and currents. In Proceedings of the 17th International Conference on Harmonics and Quality of Power (ICHQP), Belo Horizonte, Brazil, 16-19 October 2016; IEEE: Piscataway, NJ, USA, 2016; pp. 386-394. 
11. Mattavelli, P.; Marafao, F.P. Repetitive-Based Control for Selective Harmonic Compensation in Active Power Filters. IEEE Trans. Ind. Electron. 2004, 51, 1018-1024. [CrossRef]

12. Sun, B. An Improved Repetitive Control Scheme for Active Power Filter with Frequency-Adaptive Capability. In Proceedings of the 18th International Conference on Electrical Machines and Systems (ICEMS), Pattaya, Thailand, 25-28 October 2015.

13. Hornik, T.; Zhong, Q. A Current-Control Strategy for Voltage-Source Inverters in Microgrids Based on $H^{\infty}$ and Repetitive Control. IEEE Trans. Power Electron. 2011, 26, 943-952. [CrossRef]

14. Tang, Z.; Akin, B. Suppression of Dead-Time Distortion Through Revised Repetitive Controller in PMSM Drives. IEEE Trans. Energy Convers. 2017, 32, 918-930. [CrossRef]

15. Mattavelli, P.; Tubiana, L.; Zigliotto, M. Torque-Ripple Reduction in PM Synchronous Motor Drives Using Repetitive Current Control. IEEE Trans. Power Electron. 2005, 20, 1423-1431. [CrossRef]

16. Yang, Y.; Zhou, K.; Blaabjerg, F. Enhancing the Frequency Adaptability of Periodic Current Controllers with a Fixed Sampling Rate for Grid-Connected Power Converters. IEEE Trans. Power Electron. 2016, 31, 7273-7285. [CrossRef]

17. Chen, H.; Liu, H.; Xing, Y.; Hu, H. Enhanced DFT-Based Controller for Selective Harmonic Compensation in Active Power Filters. IEEE Trans. Power Electron. 2019, 34, 8017-8030. [CrossRef]

18. Yang, Y.; Zhou, K.; Blaabjerg, F. Current Harmonics from Single-Phase Grid-Connected Inverters-Examination and Suppression. IEEE J. Emerg. Sel. Top. Power Electron. 2016, 4, 221-233. [CrossRef]

19. Dannehl, J.; Wessels, C.; Fuchs, F.W. Limitations of Voltage-Oriented PI Current Control of Grid-Connected PWM Rectifiers with LCL Filters. IEEE Trans. Ind. Electron. 2009, 56, 380-388. [CrossRef]

20. Lee, G.; Kim, S.; Hong, J.; Bahn, J. Torque Ripple Reduction of Interior Permanent Magnet Synchronous Motor Using Harmonic Injected Current. IEEE Trans. Magn. 2008, 44, 1582-1585.

21. Liu, J.; Li, H.; Deng, Y. Torque Ripple Minimization of PMSM Based on Robust ILC Via Adaptive Sliding Mode Control. IEEE Trans. Power Electron. 2018, 33, 3655-3671. [CrossRef]

22. Lai, C.; Feng, G.; Iyer, K.L.V.; Mukherjee, K.; Kar, N.C. Genetic Algorithm-Based Current Optimization for Torque Ripple Reduction of Interior PMSMs. IEEE Trans. Ind. Appl. 2017, 53, 4493-4503. [CrossRef]

23. Xia, C.; Ji, B.; Yan, Y. Smooth Speed Control for Low-Speed High-Torque Permanent-Magnet Synchronous Motor Using Proportional-Integral-Resonant Controller. IEEE Trans. Ind. Electron. 2015, 62, 2123-2134. [CrossRef]

24. Das, J.C. Passive Filters-Potentialities and Limitations. IEEE Trans. Ind. Appl. 2004, 40, 232-241. [CrossRef]

25. Zhang, C. A Stationary-Frame Current Vector Control Strategy for Single-Phase PWM Rectifier. IEEE Trans. Veh. Technol. 2019, 68, 2640-2651. [CrossRef]

26. Mattavelli, P.; Buso, S. Digital Control in Power Electronics, 2nd ed.; Morgan \& Claypool: San Rafael, CA, USA, 2012.

(C) 2019 by the authors. Licensee MDPI, Basel, Switzerland. This article is an open access article distributed under the terms and conditions of the Creative Commons Attribution (CC BY) license (http://creativecommons.org/licenses/by/4.0/). 